\title{
CRITICAL SUCCESS FACTORS FOR OPEN-SOURCE INNOVATION: THE CASE OF OPEN SOURCE SOFTWARE DEVELOPMENT
}

\author{
Gang Peng, Youngstown State University, gpeng@ysu.edu
}

\begin{abstract}
With the advances in information technology (IT), open-source innovation (OSI) plays an increasingly important role for virtual teams to engage in online innovative activities. Based on the theory of knowledge creation, this study builds a theoretical framework to examine the critical success factors of OSI. It is argued that, to achieve OSI success, virtual teams need to go through an iterative process of ITenabled and community-based knowledge creation, and correspondingly four critical success factors are identified for the success of OSI: strong knowledge base, intensive team communication, abundant social capital, and effective use of IT artifacts. The proposed framework is further tested using the open source software development dataset. The results strongly support the framework, and bear important implications on the success of OSI.
\end{abstract}

Keywords: virtual teams, open-source innovation, critical success factors, knowledge creation

\section{INTRODUCTION}

With the advances in information technology (IT), open-source innovation (OSI), as typified by open source software (OSS) development, has attracted increasing attention from both researchers and practitioners in recent years. The huge success of OSS projects as well as the quick prominence gained by Wikipedia, has made many believe that the OSI model could potentially revolutionize the innovation processes in much broader research areas such as biology and medicine [29]. Therefore, there is an urgency to understand how the OSI model works and how it could be leveraged to benefit business and society at large.

In literature, OSI has been studied under different titles such as private-collective innovation [29], community-based innovation [16], or user generated content [15]. In its essence, OSI draws expertise of geographically distributed individuals of various functional backgrounds to contribute voluntarily over the Internet to the innovation, which can be freely available for viewing, modifying, and distributing. Despite the quick prominence gained by OSI, little work has been done to systematically examine the

Volume X, No. 2, 2009 critical success factors for OSI model. The current research intends to contribute to this important topic.

This research examines the critical success factors for OSI through the theoretical lens of knowledge creation. It proposes a process-based theoretical framework to derive the critical success factors for OSI. The proposed framework is validated by analyzing the case of OSS development. The major contributions of the paper are the following:

- It is argued that OSI such as OSS development is essentially an IT-enabled and community-based knowledge creation process, and correspondingly it proposes a new research framework to examine the success of OSI.

- Through analyzing the innovation process of OSI, four critical success factors are identified: strong knowledge base, intensive team communication, abundant social capital, and effective use of IT artifacts.

- It compares online social networks with their offline counterparts, and proposes that, in virtual teams and online communities, co-membership is an effective mechanism to build social networks from which social capital can be derived, accumulated, and appropriated.

\section{THEORETICAL FRAMEWORK AND HYPOTHESES}

In most industries, the successful development and commercialization of innovations are essential for a firm to sustain its competitive advantage, and the growth and development of a firm depend crucially on its ability to introduce new products over time [8]. Because of this importance, numerous studies have been conducted to locate the critical success factors of innovation and new product development (e.g., $[10,21])$.

The advent of computers and the Internet has led to fundamental changes in the way individuals communicate with each other, and innovation is increasingly being conducted by a new form of organization, the virtual teams, which connect geographically distant people with no prior acquaintance and thus can cut across the boundaries of space, time, organization, and culture. Compared 
with traditional firm-based innovation, there are several unique features about OSI model. First, OSI is carried out by virtual teams where team members are geographically distributed and the innovative activities are supported and enabled by various IT artifacts. Move over, the IT artifacts supporting OSI go beyond traditional computer-mediated communication technologies (CMCT). While the early generation of IT artifacts used by virtual teams primarily focuses on such tools as email, instant messenger, teleconference, and groupware [2], the IT artifacts adopted by OSI not only support communication or simple content presentation, but also afford the capability for social networking and collaborative content development [15]. Second, and more importantly, OSI is community-based where teams situate in certain virtual community and therefore are potentially connected and interconnected [16]. Consequently, information and knowledge possessed by one team can potentially flow across the boundary of the team and diffuse within the whole community.

\section{Conceptual Model}

In this study, I examine the critical success factors of OSI from the theoretical lens of knowledge creation. Innovation and knowledge creation are intimately connected: innovation, which is a key form of knowledge creation, cannot be explained sufficiently merely in terms of information processing or problem solving; innovation can only be better understood as a process in which problems are created, defined, and then are actively solved through development of new knowledge [24]. As a matter of fact, prior literature suggests that the process of IT innovation is indeed one of knowledge creation [23].

Knowledge has been defined as "justified true belief" that increases an organization's capacity for effective actions [25]. Although knowledge has been categorized in various ways (e.g., $[4,22])$, it is most widely conceptualized as composed of two dimensions: tacit and explicit [1, 25]. The tacit dimension is based on experience, insights, and intuitions in a specific context, while the explicit dimension of knowledge is articulated, codified, and communicated using symbols [25]. The process of knowledge creation has been depicted as a continuous dialogue between tacit and explicit knowledge via four modes of interactions, i.e., socialization, combination, internalization, and externalization [4, 24]. For this study, externalization is particularly of interest since OSI is the process of expressing ideas and solutions to problems as computer codes or online digital documentation. The above analysis of the process of knowledge creation

Volume X, No. 2, 2009 has direct bearing in identifying the critical success factors required for successful OSI.

First, knowledge is created by and also resides with individuals within teams [24, 27], therefore the knowledge base of the individuals determines to a large extent the final form of the innovation. Second, each team consists of several members who possess relevant knowledge base for OSI. All the members within a team are connected either directly or indirectly so that they can engage in social interactions with each other. Third, since OSI is community-based [16], information and knowledge created by each individual teams can flow across the boundaries of the teams. Thus, the results of the innovation also depend on the exchange of information and knowledge with other teams through various social ties and channels, i.e., the social capital possessed by the team. Lastly, team members rely on various IT artifacts to communicate, facilitate, coordinate, and perform their tasks and work processes. Based on the above analysis of the OSI process, four factors come to prominent position: knowledge base, team communication, social capital, and IT artifacts.

\section{Knowledge Base}

Knowledge resides within individuals and knowledge creation is a path-dependent process [24, 27]. The starting point of knowledge creation is tacit knowledge, which has both cognitive and technical components. The cognitive component refers to an individual's mental models, maps, beliefs, paradigms, and viewpoints; the technical component refers to concrete know-how and skills that apply to a specific context. In the process of knowledge creation, individuals accumulate tacit knowledge through direct "hands-on" experience [23]. In traditional offline teams, knowledge base has been identified as one of key factors of knowledge creation success, and its role is the most salient in activities such as preliminary technical assessment, product development, product testing, and trial pilot product [8]. For knowledge work, the most important resource is expertise. A solid knowledge base will lead to stronger problem solving capabilities, which is required for knowledge creation. Through the application of problem solving capability, teams create new knowledge and subsequently create the basis of improved innovative performance.

Research also suggests that although some innovation comes from brand new ideas, most of the innovations are the results of re-combination of existing knowledge [11]. In other words, the creation of new knowledge occurs through the application and exploitation of current information and knowledge, that is, it is created through actions and behaviors 
such as problem-solving and integration with the existing knowledge stock. Thus, a positive relationship between team knowledge base and OSI success is hypothesized:

HYPOTHESIS 1: Strong team knowledge base is positively related to the success of OSI.

\section{Team Communication}

The importance of communication to virtual team has been examined extensively. However, most of studies so far focus on how IT has changed the nature of communication, rather than looking at why communication is important for innovative activities such as OSI. For example, when communication moves online, important properties for face-to-face communication such as co-presence, visibility, audibility, co-temporality, simultaneity, and sequentiality are absent [7]. Therefore, the result of the online communication is not a conversation, but a series of intermittent, one-directional comments. In this study, rather than focus on how IT has changed the nature of communication online, I focus on the role communication plays to instigate and ferment OSI.

Knowledge creation process such as OSI has been considered as the process of communication and information processing such that task performance is greatly influenced by the quality of the communication. Consequently, the ability to communicate and collaborate is called a metacapability [20]. Communication within a team is vital for knowledge creation for several reasons. First, Knowledge creation consists of processes of distributed cognition since quite often the problems are too complex to be dealt with by a single person, and therefore team communication is needed for both "perspective making" and "perspective taking" [5]. Communication between individuals is helpful for idea generation since it permits rapid feedback, recoding and synthesis of complex information. Second, communication helps reduce uncertainty and risks associated with knowledge creation. As depicted in the classical knowledge creation process [24], socialization requires interaction between individuals through mechanisms such as observation, imitation, or apprenticeships. As the level of communication increases, individuals will be able to access more information and make more interpretation, thus resulting in new individual knowledge [1], which eventually leads to the success of innovation. Therefore, I propose the following:

HYPOTHESIS 2: Intensive communication within a team is positively related to the success of OSI.

Volume X, No. 2, 2009

\section{Social Capital}

Literature on knowledge creation traditionally focuses on information exchange within teams or organizations, and seldom do researchers examine information exchange between teams or organizations. With online communities emerging as increasingly important places for knowledge creation, the traditional knowledge creation theory has been extended beyond the boundaries of teams or organizations [16], and correspondingly I stress the community-based nature of OSI model. The immediate implication is that, for effective OSI activities, social capital of virtual teams has to be taken into consideration.

Social capital has been defined as the resources available to an actor as a function of her location in the structure of relationships. Prior literature suggested that social capital has various dimensions (e.g., [22, 27]). However, researchers have predominantly focused on the structural dimension of social capital, i.e., the structure of the network in which social actors are situated (e.g., $[19,26])$. This study follows this structuralist tradition of social capital and focuses on the network ties a virtual team maintains with other teams through co-membership.

The effect of social capital has been studied under various settings. Studies identify that group social capital contributes positively to group effectiveness in forms of inter-group horizontal bridging and intergroup vertical bridging [26], and social ties are positively related to group performance [19]. Special attention has been paid to the role of "boundary spanners", who can pull in important information to maintain team effectiveness. Recent studies also show that social capital can enhance knowledge integration, which further improves quality of decision-making [27].

The important role of social capital goes beyond resource and knowledge acquisition. For example, social capital can also potentially reduce transaction costs, search costs, bargaining and decision cost, policing and enforcement costs [17]. Social capital is particularly important for innovative and knowledge intensive activities such as OSI. First, these activities typically require performing non-routine tasks that need to draw from a variety of expertise and knowledge, some of which may lie outside a team's boundary. Therefore, having good contacts with other teams who hold these expertise and knowledge, as well as complementary resources, is crucial to the success of OSI. Second, to achieve OSI success, teams need to actively search for new ideas, opportunities, and available resources. Team social capital can potentially reduce the search cost incurred 
since they provide easy access to potentially beneficial information, untapped opportunities, and new resources that are not known to other teams and groups. Third, social capital also reduces decision cost since they offer opportunities of learning from others. Innovative activities often require evaluating alternative solutions, which consumes scarce resource such as time, energy, cognitive or computational efforts. By taking advantage of others' experience and expertise, teams can economize the cost of decision-making, save their scarce cognitive efforts and resources, and improve the odds of making the right decision. Thus the following hypothesis is formulated:

HYPOTHESIS 3: Team social capital is positively related to the success of OSI.

\section{IT Artifact}

OSI is IT-enabled, and the support of various IT artifacts is indispensable to the success of OSI. More importantly, it is argued here that the success of OSI depends on the availability and use of multiple IT artifacts rather than any single one of them. First, IT artifacts vary in the tasks they support. Broadly speaking, various IT artifacts for OSI can be roughly categorized as communication IT or repository IT. Communication IT facilitates exchange of information both within and between teams while repository IT can be used to capture, store, integrate, retrieve, and distribute knowledge created by teams. Therefore successful OSI activities need the support of both types of IT artifacts. Second, communication IT artifacts vary in their media richness, social presence, and interactivity, etc. [18]. Thus multiple IT artifacts allow virtual teams to locate and adopt the technologies that best match their tasks [2, 14]. Third, various IT artifacts also vary in their potential in motivating collaboration and contribution. For example, IT artifacts that commands richer social context will make the collaboration process stickier, and arouse the awareness of the contributors to provide more incentives for contribution. In addition, IT artifacts also can improve the level of monitoring [12], thus can potentially sanction online loafing. Forth, during the process of communication and collaboration, the preferred IT artifact is different for each individual team member, thus there is unlikely to be any one particular IT artifact that outperforms others in the collaboration process [18]. Therefore, multiple or even redundant IT artifacts are necessary for successful OSI. The above analysis leads to the following:

HYPOTHESIS 4: The availability and use of multiple IT artifacts is positively related to the success of OSI.

Volume X, No. 2, 2009

\section{DATASET, VARIABLES, AND ESTIMATION MODELS}

To empirically validate our theoretical framework, I make use of the OSS development dataset hosted by SourceForge.net. As many have pointed out, OSS model is the foundation of OSI model, and indeed the majority of research on OSI is using OSS model as an illustration [16, 29].

At SourceForge, OSS projects are developed at team or project level, and each project represents a virtual team. From its humble beginning by a few dedicated programmers, the OSS movement has now grown to over 100,000 projects with over one million registered users on SourceForge.net, the largest OSS development and collaboration web site [30].

The independent variables used for this study are extracted and derived from the January 2006 SourceForge data dump. SourceForge asks all project members to reveal their skill categories and skill experiences. The technical capacity or the knowledge base of a team is measured as the average of the skill experience (in years) of all team members. I use the $\log$ of the total number of posts on the projects' discussion forums to measure the intensity of team communication. The more posts a project's discussion forums have, the more ideas can be exchanged and potentially more learning can be facilitated and knowledge generated.

Critical to this research is to build online social network and derive online social capital. In realworld contexts, interactions between social actors are established through physical contacts, whereas contacts in online settings happen when actors "meet" virtually. When virtual teams are adopted to perform various tasks such as OSI, the same individuals can potentially participate in multiple teams, who then share these members. Consequently, connections between two different teams can be established through these co-members, who can potentially channel useful information and resources across the team boundaries. Thus co-membership is one of the most important mechanisms through which online social networks are built and online social capital can be derived and appropriated. To calculate online social capital within the OSS community, for each of the teams, I identify all the other projects connected by its co-members, , and correspondingly social capital is measured using degree centrality, counting all the other projects the current project members participated.

SourceForge provides several IT artifacts for project development, and among them, four are most important: email list, discussion forum, bug tracking 
system, and version control system. Discussion forums and email lists can potentially provide venues for members to exchange view, ideas, and facilitate knowledge generation. Bug-trackers provide interfaces with members, whose feedbacks can be used to help improve the quality of OSS. Version control systems play the role of repository IT. In the process of OSS, geographically distributed members contribute their codes via the Internet, and no single person could ever be expected to trace, organize, and integrate the huge amount of code inputs, and it is the software version control system that makes OSS a reality. Consistent with prior literature [14], variable IT artifact is measured as the count of the total number of IT artifacts that are actually used for the development of each of the OSS projects.

In order to rule out alternative explanations that could contaminate our results, I also control for two groups of control variables. The first group includes project size and project age. Project size is measured as the total number of members on each team, and project age is measured as the total months since the project is registered in SourceForge till January 2006. The second group of control variables includes some key project characteristics such as intended audience, project topic, operating system, etc.

The dependent variable is OSI success. Literature has suggested various measures for the success of OSS projects. For example, Crowston et al. [9] propose that OSS success can be measured from the following four dimensions: system creation and maintenance, system quality, system use, and system consequence. Thus, this study adopted a composite measurement, the activity percentile, which is based on a variety of performance indexes such as software download, page view, and development activities [3]. To explicitly account for this causality issue, I use the independent variables in January 2006 to predict the OSS project success afterwards. More specifically, I extracted the monthly project activity percentile from February to October 2006 data dump, and use their average over this 9-month period as the dependent variable, OSI success. By doing this, it is specified that the success of projects at later time is determined by the social network structure at an early time, and not vice versa. The final sample includes 1,572 projects. Finally, OLS model is used for result estimation.

\section{RESULTS}

The descriptive statistics and correlation matrix of the variables are shown in Table 1 . The results show that OSI success is positively correlated with knowledge base, communication, social capital, and IT artifact. These patterns are consistent with the hypotheses.

The OLS estimation results for the four hypotheses are shown in Table 2. There are three models listed in the Table. Model 1 is the base model, and it shows that, without any control variables, the coefficients on knowledge base, communication, social capital, and IT artifact are positive and significant. When the two groups of control variables are entered in Model 2 and 3 incrementally, the results remain the same as in Model 1. Therefore, all four hypotheses are strongly supported.

\section{DISCUSSION}

In this study, taking advantage of the intimate link between OSI and knowledge creation, I propose a new research framework to examine the critical success factors for OSI. The results of this study have both theoretical and practical implications.

Critical success factors for traditional innovation have been extensively researched, and a variety of both internal and external factors that could potentially impact the success of innovation has been identified [21]. One of the important conclusions from prior literature is that, depending on the tasks to perform, the success factors might differ. However, since the tasks teams perform are information and knowledge intensive, this study focused on the critical success factors as hypothesized.

One of the important finding of this study is the impact of social capital of OSI. The dominant theory about how teams affect innovation performance focuses on the "right stuff", the properties of the team itself, such as teamwork quality and team characteristics. Very few have examined if and how the social capital is important for innovation [28]. Studies of social capital's impact on online innovation are even sparse. Social capital requires networking. But due to the limitations of technologies, networking in virtual work was not as easy and effective as in the real world $[12,13]$. Thus, early literature tends to focus on the negative sides of distributed work in virtual space. However, the situation has changed substantially with the advances of new technologies, particularly the host of technologies under the umbrella of Web 2.0. Correspondingly, this study argues that online social capital contributes positively to the success of OSI. But the benefits of social capital do not accrue automatically. Thus, teams that make use of OSI model need to actively plan for and manage their network ties so to tap into the "collective intelligence" of the whole community. 
Table 1. Descriptive Statistics and Correlation Matrix

\begin{tabular}{|c|c|c|c|c|c|c|c|}
\hline Variables & $\begin{array}{l}\text { Mean } \\
\text { (s.d) }\end{array}$ & 1 & 2 & 3 & 4 & 5 & 6 \\
\hline 1. OSI success & $\begin{array}{r}74.090 \\
(22.213)\end{array}$ & - & & & & & \\
\hline 2. Knowledge base & $\begin{array}{r}2.829 \\
(0.600)\end{array}$ & $0.185^{* * *}$ & - & & & & \\
\hline 3. Communication & $\begin{array}{r}2.074 \\
(1.890)\end{array}$ & $0.404 * * *$ & $0.075 * * *$ & - & & & \\
\hline 4. Social capital & $\begin{array}{r}8.120 \\
(10.411)\end{array}$ & $0.366 * * *$ & $0.135 * * *$ & $0.290 * *$ & - & & \\
\hline 5. IT artifact & $\begin{array}{r}3.112 \\
(0.832)\end{array}$ & $0.504 * * *$ & $0.122 * * *$ & $0.365 * * *$ & $0.286 * * *$ & - & \\
\hline 6. Size & $\begin{array}{r}5.580 \\
(5.974)\end{array}$ & $0.210 * * *$ & $0.072 * * *$ & $0.272 * * *$ & $0.632 * * *$ & $0.234 * * *$ & - \\
\hline 7. Age & $\begin{array}{r}53.570 \\
(15.586)\end{array}$ & $0.184 * * *$ & $0.094 * * *$ & 0.227 & $0.249 * * *$ & $0.251^{* * *}$ & $0.226^{* * *}$ \\
\hline
\end{tabular}

Note: $\mathrm{N}=1,572 . * * * p<0.01$.

Table 2. Estimation Results for OSI Success

\begin{tabular}{|c|c|c|c|}
\hline Independent Variables & Model 1 & Model 2 & Model 3 \\
\hline Knowledge base & $\begin{array}{l}3.733 * * * \\
(0.763)\end{array}$ & $\begin{array}{l}3.693 * * * \\
(0.760)\end{array}$ & $\begin{array}{l}2.708 * * * \\
(0.762)\end{array}$ \\
\hline Communication & $\begin{array}{l}2.478 * * * \\
(0.262)\end{array}$ & $\begin{array}{l}2.601 * * * \\
(0.263)\end{array}$ & $\begin{array}{l}2.641 * * * \\
(0.264)\end{array}$ \\
\hline Social capital & $\begin{array}{l}0.391 * * * \\
(0.047)\end{array}$ & $\begin{array}{l}0.534 * * * \\
(0.058)\end{array}$ & $\begin{array}{l}0.455^{* * * *} \\
(0.059)\end{array}$ \\
\hline IT artifact & $\begin{array}{l}9.920 * * * \\
(0.605)\end{array}$ & $\begin{array}{c}10.143 * * * \\
(0.611)\end{array}$ & $\begin{array}{l}9.943 * * * \\
(0.606)\end{array}$ \\
\hline Size & & $\begin{array}{c}-0.423 * * * \\
(0.102)\end{array}$ & $\begin{array}{c}-0.394 * * * \\
(0.103)\end{array}$ \\
\hline Age & & $\begin{array}{c}-0.019 \\
(0.031)\end{array}$ & $\begin{array}{c}-0.020 \\
(0.032)\end{array}$ \\
\hline $\mathrm{R}^{2}$ & 0.355 & 0.362 & 0.400 \\
\hline
\end{tabular}

Notes: $\mathrm{N}=1$,572. Dependent variable is OSI success. Estimated coefficients and their associated standard errors (in parentheses) are listed under each model. $* * * p<0.01$. Other independent variables in Model 3 include 5 dummy variables for the intended audience of the projects, 5 dummy variables for operating systems, and 19 dummy variables for project.

The finding that multiple IT artifacts are more conducive to OSI also has important implications. Too often, managers tend to chase after the latest technologies to support their distributed work. By doing this, however, they ignored the fact that which technologies perform better depends not only on the technologies themselves, but also on the tasks to be performed as well as the individuals using the technologies. When no clear decisions can be made or the objective is to cater to a vast variety of users as in the case of OSI, multiple or even redundant IT artifacts seems to be a better choice. 
The findings also have important implications for open innovation in general. Similar to OSI, open innovation also draws inspiration from OSS development [6]. However, rather than operate at the level of virtual teams, open innovation is the strategy recommended for firms. The central theme of open innovation is that during the innovation processes, firms' boundaries should be porous, since they need to interact with their environments to explore and also exploit external resources and technologies. While open innovation correctly emphasizes the importance for firms to enter into collaborative network arrangements with business partners, it seems not to emphasize enough the importance of firm's own capabilities. While the findings from this study echo the importance of social capital to firm performance, it also suggests that it is equally important to pay attention to the knowledge base and capabilities of the firms as well. Social capital is not a panacea, and in many case, without properly developed capabilities to recognize, assimilate, and make use of the external information and resources afforded by networked partners, the firms cannot appropriate rents from these resources.

\section{CONCLUSION}

While technologies continue to evolve with their fast pace, one can only imagine that OSI will play a more important role in the future for online collaboration and innovation. Therefore, identifying critical success factors for OSI model is of utmost importance. The IT-enabled and community-based knowledge creation mode as proposed in this study represents an initial step toward this effort. However, this study has its own share of limitation. First, it uses the data from OSS project, a "free" digital product. Thus one interesting extension of future studies may be to examine variations of the proposed framework under proprietary products. Second, this study assumes that all the four critical factors affect OSI success uniformly, and future studies may examine possible contingencies of these critical success factors. In addition, there are interesting research opportunities in studying how cultural and emotional factors such as virtual team identity, trust, task coordination, and conflict management can potentially affect OSI success.

\section{REFERENCES}

1. Alavi, M., Leidner, D. E.. 2001. Knowledge management and knowledge management systems: Conceptual foundations and research issues. MIS Quarterly 25(1) 107-136.
2. Bajwa, D. S., Lewis, L. F., Pervan, G., Lai, V. S., Munkvold, B. E., Schwabe, G. 2008. Factors in the global assimilation of collaborative information technologies: An exploratory investigation in five regions. Journal of Management Information Systems 25(1) 131-165

3. Barbagallo, D., Francalenei, C., Merlo, F. 2008. The impact of social networking on software design quality and development effort in open source projects. ICIS 2008 proceedings.

4. Becerra-Fernandez, I., Sabherwal, R. 2001 Organizational knowledge management: A contingency perspective. Journal of Management Information Systems 18(1) 23-55.

5. Boland, R. J., Tenkasi, R. V. 1995. Perspective making and perspective taking in communities of knowing. Organization Science 6(4) 350-372.

6. Chesbrough, H. W. 2003. Open Innovation: The New Imperative for Creating and Profiting from Technology. Boston: Harvard Business School Press.

7. Clark, H. H., Brennan, S. E. 1991. Grounding in communication. In L. B. Resnick, J. M. Levine, \& S. D. Teasley (Eds.), Perspectives On Socially Shared Cognition (pp. 127-149). Washington, DC, USA: American Psychological Association.

8. Cooper, R. G. 1990. New products: What distinguishes the winners. Research Technology Management 33(6) 27-31.

9. Crowston, K., Howison, J., Annabi, H. 2006. Information systems success in free and open source software development: Theory and measures. Software Process-Improvement and Practice 11(2) 123-148.

10. Ernst, H. 2002. Success factors of new product development: A review of the empirical literature. International Journal of Management Review 4 1-40.

11. Fleming, L., Waguespack, D. M. 2007. Brokerage, boundary, spanning, and leadership in open innovation communities. Organization Science 18(2) 165-180.

12. Hinds, P., Bailey, D. 2003. Out of sight, out of sync: Understanding conflict in distributed teams. Organization Science 14 615-632.

13. Jarvenpaa, S. L., Leidner, D. 1999. Communication and trust in global virtual teams. Organization Science 10(6) 791-815.

14. Jarvenpaa, S., Majchrzak, A. 2008. Knowledge collaboration among professionals protecting national security: Role of transactive memories in ego-centered knowledge networks. Organization Science 19(2) 260-276.

15. Lai, L. S. L., Turban, E. 2008. Groups formation and operations in the Web 2.0 environment and social networks. Group Decision and Negotiation 17 387-402. 
16. Lee, G., Cole, R. 2003. From a firm-based to a community-based model of knowledge creation. Organization Science 14(6) 633-649.

17. Maskell, P. 2000. Social Capital, innovation and competitiveness, in S. Baron, J. Field, T. Schuller (Eds.) Social Capital: Critical Perspective, Oxford University Press, Oxford.

18. Massey, A. P., Montoya-Weiss, M. M. 2006. Unraveling the temporal fabric of knowledge conversion: A model of media selection and use. MIS Quarterly 30(1) 99-114.

19. Mehra, A., Dixon, A. L., Brass, D. J., Robertson, B. 2006. The social network ties of group leaders: implications for group performance and leader reputation. Organization Science 17(1) 64-79.

20. Miles, R. E., Snow, C. C., Miles, G. 2000. The future organizations. Long Range Planning 33 300-321.

21. Montoya-Weiss, M., Calantone, R. 1994. Determinants of new product performance: A review and meta-analysis. Journal of Product Innovation Management 11(5) 397-417.

22. Nahapiet, J., Ghoshal, S. 1998. Social capital, intellectual capital, and the organizational advantage. Academy of Management Review 23 242-266.

23. Nambisan, S., Agarwal, R., Tanniru, M. 1999. Organizational mechanisms for enhancing user innovation in information technology. MIS Quarterly 23(3) 365-395.

24. Nonaka, I. 1994. A dynamic theory of organizational knowledge creation. Organization Science 5(1) 14-37.

25. Nonaka, I., Takeushi, H. 1995. The Knowledgecreating Company. New York: Oxford University Press.

26. Oh, H., Chung, M., Labianca, G. 2004. Group social capital and group effectiveness: The role of informal socializing ties. Academy of Management Journal 47(6) 860-875.

27. Robert, L., Dennis, A., Ahuja, M. 2008. Social capital and knowledge integration in digitally enabled teams. Information Systems Research 19(3) 314-334.

28. Stewart, G. A. 2006. Meta-analytic review of relationships between team design features and team Performance. Journal of Management 32(1) 29-55.

29. von Hippel, E., von Krogh, G. 2003. Open source software and the "private-collective" innovation model: Issues for organization science. Organization Science 32(2) 209-233.

30. Xu, J., Christley, S., Madey, G. 2006. Application of social network analysis to the study of open source software, in The Economics of Open Source Software Development, edited by J. Bitzer and P. Schroder, Elsevier Science. 